\title{
Cultural modifications of cognitive behavioural treatment of social anxiety among culturally diverse clients: a systematic literature review
}

\author{
Maja Jankowska* \\ School of Psychology, University of Bedfordshire, University Square, Luton, UK
}

Received 1 March 2018; Accepted 18 September 2018

\begin{abstract}
The aim of this study was to conduct a systematic literature review to ascertain whether cognitive behavioural therapy (CBT) for social anxiety disorder (SAD) can be successfully used in non-Western contexts and demonstrate sufficient effectiveness. This area is largely under-researched with conflicting evidence presented in quantitative studies, with virtually no qualitative studies published. This review utilized realist review methodology and focused on qualitative case studies presented by clinicians. A systematic search of EBSCO HOST, The Cochrane Library Database, Google, Google Scholar and reference mining, using various combinations of terms relating to: (1) CBT, (2) social anxiety and (3) cultural diversity were employed. Seven case studies of cultural adaptations of CBT treatment for culturally diverse SAD sufferers were included. The treatment outcomes were generally promising in all cases (reporting significant decrease of SAD symptoms, maintained over time) and the success of therapy was often attributed to culturally specific modifications introduced. CBT can be an acceptable and effective treatment for culturally diverse SAD sufferers with 'modest' modifications, without major diversions from the original CBT models and protocols, but this finding must be treated with caution and more methodologically rigorous research (qualitative and quantitative) is needed to more fully understand what works, for whom and in what circumstances.
\end{abstract}

Key words: case studies, cognitive behaviour therapy, cultural adaptations, social anxiety disorder, treatment

\section{Introduction}

Cognitive behavioural therapy (CBT) for the treatment of social anxiety disorder (SAD) has demonstrated efficacy in numerous research studies (Hofmann and Smits, 2008), systematic reviews (Voss Horrell, 2008;) and meta-analyses (Acaturk et al., 2009; Stewart and Chambless, 2009). However, most of these were conducted in Europe and North America

\footnotetext{
*Correspondence to Dr Maja Jankowska, School of Psychology, University of Bedfordshire, University Square, Luton LU1 3JU, UK (email: maja.jankowska@beds.ac.uk)
} 
(limiting their universal applicability) and less is known about the efficacy of CBT for ethnic minorities and other under-represented groups (Weiss et al., 2011). Moreover, the theoretical orientations underlying CBT models and treatment interventions developed in Western countries are constrained by Western conceptualizations of SAD (Yoshinaga et al., 2013).

This article aims to familiarize readers with the overview of the literature on cultural aspects of SAD and enable them to consider whether cultural adaptations to the treatment protocol of SAD are necessary, and if so, to what extent. It aims to encourage practitioners to reflect on their own practice and potential cultural modification they may consider. It also aims to encourage researchers to conduct further research, taking the research beyond the approach of the case studies.

\section{Cultural factors of social anxiety disorder}

As Kleinknecht et al. (1997) observe, the experience of intense anxiety or fear associated with social situations in which one might be viewed or scrutinized by others seems to be a universal phenomenon. However, cultural factors can complicate the symptom presentation (Ashworth et al., 2011) and it is likely that there are numerous cultural variations, both in the expression of such anxiety and in the situations and socio-cultural contexts in which it is elicited (Kleinknecht et al., 1997). For instance, taijin-kyofu-sho (TKS) which was listed in the appendix to DSM-IV (Chapman et al., 2013) as a culture-specific syndrome unique to East Asian populations, emphasizes a potential construction of social anxiety as not concerned with embarrassing or humiliating oneself (typical Western conceptualization of SAD) but with offending or making others uncomfortable (Hofmann et al., 2010; Leslie, 2013; Shirotsuki et al., 2014; Stein, 2009; Yoshinaga et al., 2013). This focus on offending others reflects important cultural differences between West and East, particularly the value given to the group far above the needs of an individual in traditional Eastern Asian societies. Other collectivistic cultures (e.g. Arab culture, McIndoo and Hopko, 2014; or ultra-orthodox Jewish communities, Greenberg et al., 2004) illustrate an interplay of strict social and religious norms that govern interactions within society and can lead to the development of culturally specific symptoms of anxiety.

Despite cultural differences in conceptualizations of SAD, SAD sufferers around the globe have many features in common. The overlap between different TKS categories and other anxiety disorders common in the Western world can be seen in DSM-V (American Psychiatric Association, 2013; Stein, 2009; Hofmann et al., 2010). Moreover, there is a growing body of evidence indicating that CBT can be an effective treatment for patients in Eastern cultures, even without employing systematic cultural adaptations (Chen et al., 2007; Voss Horrell, 2008; Yoshinaga et al., 2013).

Arguably, cultural differences influence the process of psychotherapy and therefore therapy might need adapting to the cultural needs of patients (Iwamasa, 2003; Sue and Sue, 2008). This may increase acceptability of the treatment, patient satisfaction and, ultimately, its effectiveness (Bernal and Scharrón-del-Río, 2001; Sue, 2003; Castro et al., 2010). Several professional organizations have issued standards and guidelines to help improve the delivery of psychological treatments for ethnic minority clients, including the need to take into account cultural norms and socio-cultural contexts, and the recommendation to tailor and provide culturally sensitive treatment (Council of National Psychological Associations for 
the Advancement of Ethnic Minority Issues, 2003; American Psychological Association, 1990). Overall, the literature examining the impact of group membership on the treatment outcome, tailoring the treatment or developing new treatments for ethnic minorities has been slow and sparse (Carter et al., 2012). There is some evidence that modifications ranging from minor (ethnic matching, use of a culturally sensitive therapist, use of culturally appropriate examples) to major (utilization of strategies rooted in the culture, e.g. eastern philosophy, incorporation of extended family) can produce beneficial effects (Carter et al., 2012). Yet, the amount and scope of modifications required to make these treatments effective as well as their cost effectiveness remains disputed (Castro et al., 2010; Chawdhary et al., 2014).

\section{Culturally sensitive treatments of SAD}

Despite the awareness of the need to provide culturally sensitive treatments, Voss Horrell (2008) argues that few studies examine the applicability of CBT treatment for ethnic minority clients and Weiss et al. (2011) note the paucity of research addressing the effectiveness of CBT treatment specifically for SAD patients of various cultural backgrounds.

So far there has been no systematic literature conducted on culturally specific adaptations of CBT to culturally diverse SAD patients. Van Loon et al. (2013) conducted a systematic review of culturally adapted treatments for anxiety and depression, concluding that adapting interventions to better suit them to specific ethnic minority groups is 'worthwhile' but none of the studies they reviewed looked at SAD.

\section{Aims of the present review}

The available quantitative literature seems to indicate that CBT treatment for SAD can be successfully used in non-Western contexts (Chen et al., 2007; Shirotsuki et al., 2013) and demonstrate sufficient effectiveness. However, most quantitative studies indicated that some modifications were made but their extent, scope and focus was not made explicit or discussed in any depth. In the light of the above issues, this literature review focuses on qualitative case studies among culturally diverse SAD sufferers and aims to appraise qualitative literature in an attempt to answer the following questions: (1) Are culturally specific modifications required when applying CBT to culturally diverse SAD sufferers?; and (2) Do culturally specific modifications of CBT treatment for culturally diverse SAD sufferers increase the treatment compliance and its outcomes, and if so, in what way?

\section{Method}

\section{Design}

The design is a systematic literature review of qualitative case studies using realist review methodology.

As quantitative research does not provide readers with the details regarding cultural modifications made when applying CBT for SAD among diverse clients, a qualitative literature review was chosen, with a specific focus on detailed case studies. Because of their in-depth focus with contexts, case studies can provide information that contributes to our 
Table 1. The criteria for inclusion of case studies

\begin{tabular}{ll}
\hline Participants & $\begin{array}{c}\text { Clients of all ages, coming from ethnic minority backgrounds, in a variety of } \\
\text { locations, but all suffering predominantly from SAD and receiving culturally } \\
\text { adapted/modified CBT treatment for SAD } \\
\text { Qualitative studies } \\
\text { Case studies }\end{array}$ \\
Outcome & Studies which explore: cultural factors in the delivery of CBT for ethnic minority \\
& SAD sufferers, the need for cultural adaptations/modifications of CBT treatment \\
& for SAD, effectiveness of cultural adaptations/modifications of CBT treatment \\
for SAD & \\
Time frame & Studies published in the last 20 years (1996-2016)
\end{tabular}

Exclusion criteria: non-English language literature, studies published before 1996, quantitative studies, book reviews.

understanding of cultural dilemmas and framing therapeutic decisions made when working with culturally diverse clients. Realist review methodology (Pawson et al., 2005) was chosen as it 'provides an explanatory analysis aimed at discerning of what works for whom, in what circumstances, in what respects and how' (p. 21) and because it attends to the assumptions about how the intervention should work and what impacts it is expected to have. It then looks for empirical evidence for supporting, contradicting or modifying the intervention theory. The aim is not to ascertain whether something works or not, but to provide the intervention decision makers and practice community with rich, detailed and highly practical understanding of interventions, which is likely to be of much more use to them (Pawson et al., 2005). Table 1 shows the criteria for inclusion of case studies.

\section{Data sources}

Electronic searches of the EBSCO HOST, The Cochrane Library Database, Google, Google Scholar and reference mining, using various combinations of terms relating to: (1) CBT, (2) social anxiety and (3) cultural diversity were employed.

\section{Realist review methodology - stages of the literature search strategy}

Realist review methodology advocates conducting literature searches in the following stages:

(1) A background search to get a feel of literature - what is there, what form it takes, where it seems to be located, and how much there is.

(2) Progressive focusing to identify the competing theories.

(3) A search for empirical evidence - a more formal stage, moving away from browsing. For this stage a formal audit trail should be provided.

(4) A final search once the synthesis is almost complete - to seek out additional studies that may further refine the intervention theories that have formed the focus on analysis. 
In line with the above, the following was conducted:

(1) Prior to embarking on this review, a search for systematic reviews was conducted. No systematic reviews using qualitative approaches for culturally specific adaptations when applying CBT to ethnic minority patients suffering from SAD were found. It was also noted that there were also no quantitative systematic literature reviews conducted on that topic. The most complete and up-to-date meta-analysis of the efficacy of CBT approaches to treating SAD sufferers was conducted in 2009 by Acarturk, Cuijpers, van Straten and de Graaf, but several major methodological weaknesses were found in this as well as previous reviews (Hunsley et al., 2014).

(2) Identification of competing theories: to become more familiar with the literature, a background search was conducted (Google, Google Scholar). This sensitized the researcher to the debate around considering cultural variations of SAD, including culturebound disorders such as taijin-kyofu-sho (TKS), which is listed in the appendix to DSM-IV as a culture-specific syndrome unique to East Asian populations and in which an individual is not concerned with embarrassing or humiliating oneself but with offending or making others uncomfortable.

This led to the consideration given to whether CBT should be culturally adapted to cater for specific cultural variations of SAD, such as taijin-kyofu-sho and gave grounds to the identification of Theory 1: systematic cultural adaptations are required. Advocating a systematic, complete adaptation seems to be more of a theoretical idea, however, and such systematic cultural adaptations seem to be rare as they require a significant amount of work to change both the content of a protocol and the approach to implementation. The search did not yield any specific example of a complete, systematic adaptation of CBT for SAD.

However, further searches indicated that the argument can be made that, despite differences between the conceptualizations of SAD and taijin-kyofu-sho or other culture-specific manifestations of social anxiety, SAD sufferers around the globe have many features in common and there is a significant overlap between different TKS categories (sekimen-kyofu: fear of blushing; shubo-kyofu: fear of being stared at in public due to physical deformity; jikoshisen-kyofu: fear of own gaze/eye contact upsetting/hurting others (often translated in the literature, in a simplified way, as fear of eye contact or fear of one's own glance/face); and jikoshu-kyofu: fear of foul odour) and DSM-V disorders (Stein, 2009, Hofmann et al., 2010). Moreover, although there has been a significant concern over potential transfer of models and treatment interventions developed in the West and constrained by Western conceptualizations of SAD, there is a growing body of evidence indicating that CBT can be an effective treatment for patients in Eastern cultures, even without employing systematic cultural adaptations (Chen et al., 2007; Voss Horrell, 2008; Yoshinaga et al., 2013).

Some of the sources found in this phase of searching seemed to advocate Theory 2: no systematic cultural adaptations are required (e.g. Yoshinaga et al., 2013), while others seemed to support Theory 3: 'modest' cultural modifications may be beneficial (Chapman et al., 2013; Weiss et al., 2011). Theory 3 seems to be dominant in the area of research not only on cultural aspects of SAD but in general on culturally sensitive CBT for a variety of conditions (e.g. Husain et al., 2014, 2017; Naeem et al., 2015). Husain et al. (2017) explain that such adaptations are generally focused on implementation, rather than the content of materials. 
Therefore three competing theories have been identified:

- Theory 1: systematic cultural adaptations are required;

- Theory 2: no systematic cultural adaptations are required;

- Theory 3: 'modest' cultural modifications may be beneficial.

(3) Formal search for empirical evidence:

\section{Search strategy}

The search was conducted using:

- EBSCO HOST, which allows searching multiple databases at the same time (databases included in this search: Academic Search Elite, AMED, American Doctoral Dissertations, CINAHL plus with full text, E-Journals, ERIC, Global Health, Medline, PsychINFO, PsycARTICLES, ScienceDirect),

- The Cochrane Library Database,

- Other internet sources (using Google and Google Scholar),

- Grey literature, such as Clinical Trials: clinicaltrials.gov

(4) Finally, searching in realist review is both iterative and interactive, tracking back and forth from the literature retrieved to the research questions and intervention theories. The search strategies and terms used are likely to evolve as understanding grows (Pawson et al., 2005). Therefore, snowballing - pursuing references of references by hand or by means of citation-tracking databases - is recommended.

Given that the literature in this area appeared to be particularly limited and that realist review methodology advocates against the use of 'pre-qualification exercise' and pre-designed checklists (Pawson et al., 2005), the researcher has chosen to be broad in the inclusion of studies. This allows for the review to be as comprehensive as possible and remain open to explore 'what works for whom, in what circumstances, in what respects and how' (Pawson et al., 2005, p. 21).

The following combinations of the key search terms have been used: 'cognitive behavio* therap*', 'CBT' and 'social anxiety', 'social anxiety disorder', 'SAD' and 'cultur*', 'ethnic minorit*', 'ethnic group*', 'ethnic background', 'cultur* background', 'immigrant*', 'migrant*', 'cultur* adaptation*'. Table 2 summarizes the search outcomes.

Following the above searches, a total of four articles were included in the literature review. A further two articles were found through reference mining (Toyokawa and Nedate, 1996; Fink et al., 1996). The article by Fink et al. (1996) utilized behavioural therapy (social effectiveness treatment), rather than CBT. Nonetheless, given its focus on social anxiety for ethnic minority clients, the emphasis of all other case studies on exposure work and the format as well as the overall paucity of literature in this area, it was decided that this article should also be included in the review. This brought the number of cases included to seven case studies presented over six journal articles.

\section{Study selection}

We selected qualitative case studies that focused on applicability of CBT for the treatment of SAD for culturally diverse clients. 
Table 2. Search outcomes for each database and combination of search terms

\begin{tabular}{|c|c|c|c|c|}
\hline Database & $\begin{array}{l}\text { Combination of } \\
\text { search terms }\end{array}$ & $\begin{array}{l}\text { Number } \\
\text { of hits }\end{array}$ & $\begin{array}{l}\text { Number of } \\
\text { abstracts } \\
\text { retrieved }\end{array}$ & $\begin{array}{l}\text { Number of } \\
\text { included } \\
\text { studies }\end{array}$ \\
\hline EBSCO HOST & $\begin{array}{l}\text { 'cognitive behavio* therap*' }+ \\
\text { 'social anxiety' }+ \text { 'cultur*' }\end{array}$ & 84 & 8 & $\begin{array}{l}4 \\
5 \text { th article was a } \\
\quad \text { possibility but } \\
\quad \text { no full text } \\
\quad \text { was available }\end{array}$ \\
\hline EBSCO HOST & $\begin{array}{l}\text { 'cognitive behavio* therap"' }+ \\
\text { 'social anxiety' }+ \text { 'ethnic } \\
\text { minorit"' }\end{array}$ & 5 & 1 & $\begin{array}{l}1 \text { (already } \\
\text { included in } \\
\text { the } 4 \text { above) }\end{array}$ \\
\hline EBSCO HOST & $\begin{array}{l}\text { 'cognitive behavio* therap*' }+ \\
\text { 'social anxiety' }+ \text { 'ethnic } \\
\text { group*' }\end{array}$ & 4 & 0 & $\begin{array}{l}1 \text { (already } \\
\text { included in } \\
\text { the } 4 \text { above) }\end{array}$ \\
\hline EBSCO HOST & $\begin{array}{l}\text { 'cognitive behavio* therap*' }+ \\
\text { 'social anxiety' + 'ethnic } \\
\text { background' }\end{array}$ & 0 & 0 & 0 \\
\hline EBSCO HOST & $\begin{array}{l}\text { 'cognitive behavio* therap*' }+ \\
\text { 'social anxiety' }+ \text { 'cultur* } \\
\text { background' }\end{array}$ & 2 & 0 & 0 \\
\hline EBSCO HOST & $\begin{array}{l}\text { 'cognitive behavio* therap*' }+ \\
\text { 'social anxiety' }+ \\
\text { 'immigrant*' }\end{array}$ & 0 & 0 & 0 \\
\hline EBSCO HOST & $\begin{array}{l}\text { 'cognitive behavio* therap"' }+ \\
\text { 'social anxiety' + 'migrant*, }\end{array}$ & 1 & 0 & 0 \\
\hline EBSCO HOST & $\begin{array}{l}\text { 'cognitive behavio* therap*' }+ \\
\text { 'social anxiety' }+ \text { 'cultur* } \\
\text { adaptation*' }\end{array}$ & 0 & 0 & 0 \\
\hline EBSCO HOST & $\begin{array}{l}\text { All the combinations above with } \\
\text { 'social anxiety' replaced by } \\
\text { 'social phobia' }\end{array}$ & $\begin{array}{l}\text { No new } \\
\text { sources } \\
\text { identi- } \\
\text { fied }\end{array}$ & 0 & 0 \\
\hline $\begin{array}{l}\text { The Cochrane } \\
\text { Library }\end{array}$ & $\begin{array}{l}\text { Searches as above but without } \\
\text { truncation (not allowed in this } \\
\text { database) }\end{array}$ & 0 & 0 & 0 \\
\hline Clinical Trials & $\begin{array}{l}\text { Searches as above - each brought } \\
0 \text { results. Then a broader } \\
\text { search was employed (CBT }+ \\
\text { social anxiety) which yielded } \\
269 \text { results - but all irrelevant }\end{array}$ & 269 & 3 & 0 \\
\hline
\end{tabular}

\section{Quality appraisal}

The need for appraisal of studies before the synthesis has been questioned (Pawson et al., 2005). Realist review methodology does not support the use of pre-designed checklists and hierarchical approaches as it posits that multiple methods are needed to illuminate the richer 
picture. Therefore, the realist solution is to cut directly to the judgement as the basic realist principle on quality assessment is that 'the worth of studies is established in synthesis and not as a preliminary pre-qualification exercise' (Pawson et al., 2005, original emphasis).

\section{Data synthesis}

Realist synthesis can be centred on any the following issues:

- What is it about this kind of intervention that works?

- For whom?

- In what circumstances?

- In what respects?

- Why?

This review focuses on the question of what specific cultural modifications to the CBT treatment of culturally diverse SAD clients work, in what respects and how.

The synthesis stage should keep this focus in mind and adjudicate between rival theories, considering applications in different contexts and comparing expectations with actual practice. Within this review, the rival theories considered were:

- Theory 1: systematic cultural adaptations are required

- Theory 2: no systematic cultural adaptations are required

- Theory 3: 'modest' cultural modifications may be beneficial

Realist review is fundamentally pragmatic.

A summary of the studies selected, including the key findings, is provided in the Results section.

\section{Utilization of case studies}

Case studies are a well-established methodology in the field of Social Sciences (Yin, 2009). It is compatible with realist review methodology (Pawson et al., 2005, chosen for this review) as it may help to inform the practice by illustrating what has worked, what has been achieved and what have been the issues or dilemmas (Yin, 2009). Although single case studies have been criticized for their inability to produce generalizations (Tellis, 1997), the purpose of qualitative methodology is not to generalize but to produce rich, 'thick' descriptions of the phenomenon under research (Flick, 1995; Lincoln and Guba, 1985). Moreover, qualitative research has been pivotal in addressing the questions around the process and the context of therapy (McLeod, 2001).

Case studies can be particularly useful in the development and refinement of clinical practice and in recent years the development of methods for systematic collection and analysis of case data has made it possible for case studies to start making contributions to the evidence base for therapy policy and practice (McLeod and Elliott, 2011). They can be useful for policy makers, showcasing the examples of good and bad practice and they can also be used to highlight the value of new or under-researched interventions (McLeod and Elliott, 2011). In the case of this review, it is hoped that the case studies can help shed more light on the poorly understood and under-researched topic of cultural adaptations of CBT for the treatment of SAD in culturally diverse clients. 


\section{Results}

\section{Outline of selected studies with key findings}

This review aimed to consider whether culturally specific modifications are required when applying CBT to culturally diverse SAD sufferers. The case studies discussed within this review emphasized the importance of culturally sensitive delivery of individualized treatment and provided examples of modifications made, yet, at the same time, indicated that these modifications were usually modest and did not require significant alterations of the CBT SAD treatment, as can be seen in Table 3 below.

It is concluded that CBT can be applied to culturally diverse SAD sufferers without major modifications to the treatment.

The second aim of this review was to ascertain whether any culturally specific modifications of CBT treatment for culturally diverse SAD sufferers increased the treatment compliance and its outcomes. The authors of the reviewed cases reported significant decrease of SAD symptoms, maintained over time and the success of therapy was often attributed to culturally specific modifications introduced. However, they were rather vague when it came to ascertain what specifically increases the treatment compliance and its outcomes for culturally diverse SAD sufferers. It may be difficult to point to certain factors with a case study design as the authors are not able to control for any other factors. It is important to note that there many factors that may contribute to lasting results and that many of the features discussed in the results below also may be more generic to CBT, rather than specific to CBT for anxiety, within this client group and hence this area will require further investigation.

Despite the main finding indicating that there is no need for major or significant alternations of the CBT SAD treatment, the review indicated:

(a) the importance of awareness of different needs of culturally diverse clients,

(b) some challenges in the delivery of CBT for culturally diverse clients, and

(c) some minor adaptations that may improve adherence and engagement with therapy.

These three areas will be briefly discussed below and further elaborated on in the Discussion section.

\section{The importance of awareness of different needs of culturally diverse clients}

All reviewed case studies highlighted the importance of cultural knowledge (e.g. of cultural norms and values, Weiss et al., 2011; Yoshinaga et al., 2013; Ashworth et al., 2011; McIndoo and Hopko, 2014; Toyokawa and Nedate, 1996; Fink et al., 1996; socio-cultural and historical contexts, Yoshinaga et al., 2013; the relevance of cultural background to the presenting problems, McIndoo and Hopko, 2014), cultural sensitivity (Weiss et al., 2011; Yoshinaga et al., 2013) and the need to develop and practice cultural awareness (including being open to and frequently discussing culture, e.g. McIndoo and Hopko, 2014).

They indicated that the awareness of specific mental health needs of culturally diverse groups of clients, ways of expression of distress and reasons for reported prevalence of SAD in different cultural groups are particularly important when treating culturally diverse clients. 
Table 3. Studies and key findings regarding cultural adaptations to the CBT treatment for ethnically diverse SAD clients

\begin{tabular}{|c|c|c|c|c|c|}
\hline $\begin{array}{l}\text { Author(s), date } \\
\text { and title }\end{array}$ & $\begin{array}{l}\text { Research } \\
\text { aim }\end{array}$ & $\begin{array}{l}\text { Research } \\
\text { design }\end{array}$ & $\begin{array}{l}\text { Case study } \\
\text { context }\end{array}$ & $\begin{array}{l}\text { Recommendations } \\
\text { for clinicians }\end{array}$ & Findings \\
\hline $\begin{array}{l}\text { Weiss BJ, } \\
\text { Singh JS, } \\
\text { Hope DA } \\
\text { (2011). } \\
\text { Cognitive- } \\
\text { behavioural } \\
\text { therapy for } \\
\text { immigrants } \\
\text { presenting } \\
\text { with social } \\
\text { anxiety } \\
\text { disorder: two } \\
\text { case studies }\end{array}$ & $\begin{array}{l}\text { To demonstrate } \\
\text { culturally } \\
\text { sensitive } \\
\text { delivery of } \\
\text { individual- } \\
\text { ized } \\
\text { treatment } \\
\text { with two } \\
\text { culturally } \\
\text { diverse } \\
\text { clients }\end{array}$ & $\begin{array}{l}\text { Case studies } \\
\text { (comparative } \\
- \\
\text { comparisons } \\
\text { made between } \\
\text { two case } \\
\text { studies) }\end{array}$ & $\begin{array}{l}\text { USA } \\
1 \text { immigrant from } \\
\text { Central America } \\
\text { (male, 57, emigrated } \\
\text { to America as an } \\
\text { adult over } 30 \text { years } \\
\text { prior to treatment) } \\
\text { and } 1 \text { from China } \\
\text { (female, 37, } \\
\text { emigrated to USA } 3 \\
\text { years prior to } \\
\text { treatment). } \\
\text { CBT delivered in } \\
\text { English (with } \\
\text { elements, e.g. } \\
\text { homework, } \\
\text { completed in native } \\
\text { language). Therapist } \\
\text { and client ethnic } \\
\text { backgrounds not } \\
\text { matched }\end{array}$ & $\begin{array}{l}\text { Importance of active } \\
\text { assessment of clients' } \\
\text { language proficiency - } \\
\text { treatment tailored } \\
\text { (elements delivered in } \\
\text { native language). } \\
\text { Attention needs to be } \\
\text { paid to cultural norms } \\
\text { and values which may } \\
\text { impede access and/or } \\
\text { engagement with } \\
\text { therapy. } \\
\text { Consideration of } \\
\text { acculturation stage. } \\
\text { Importance of } \\
\text { therapeutic } \\
\text { relationship - } \\
\text { sensitive to cultural } \\
\text { aspects }\end{array}$ & $\begin{array}{l}\text { Necessary cultural } \\
\text { modifications modest, } \\
\text { suggesting therapy } \\
\text { can be conducted in } \\
\text { culturally sensitive } \\
\text { manner without much } \\
\text { deviation from the } \\
\text { treatment protocol } \\
\text { (support for Theory } \\
\mathbf{3} \text { with clear } \\
\text { recommendations for } \\
\text { modifications) }\end{array}$ \\
\hline
\end{tabular}


Table 3. Continued

\begin{tabular}{|c|c|c|c|c|c|}
\hline $\begin{array}{l}\text { Author(s), date } \\
\text { and title }\end{array}$ & $\begin{array}{l}\text { Research } \\
\text { aim }\end{array}$ & $\begin{array}{l}\text { Research } \\
\text { design }\end{array}$ & $\begin{array}{l}\text { Case study } \\
\text { context }\end{array}$ & $\begin{array}{l}\text { Recommendations } \\
\text { for clinicians }\end{array}$ & Findings \\
\hline $\begin{array}{l}\text { Yoshinaga N, } \\
\text { Kobori O, } \\
\text { Iyo M, } \\
\text { Shimizu E } \\
\text { (2013). } \\
\text { Cognitive } \\
\text { behaviour } \\
\text { therapy using } \\
\text { the Clark and } \\
\text { Wells model: } \\
\text { a case study } \\
\text { of a Japanese } \\
\text { social anxiety } \\
\text { disorder } \\
\text { patient }\end{array}$ & $\begin{array}{l}\text { To assess } \\
\text { whether } \\
\text { Clark and } \\
\text { Wells (1995) } \\
\text { model of } \\
\text { social anxiety } \\
\text { can be } \\
\text { successfully } \\
\text { employed } \\
\text { with } \\
\text { Japanese } \\
\text { SAD patient }\end{array}$ & $\begin{array}{l}\text { Single case } \\
\text { study }\end{array}$ & $\begin{array}{l}\text { Japan. } \\
\text { Japanese female client } \\
\text { (42). } \\
\text { CBT delivered in } \\
\text { Japanese by } \\
\text { Japanese psychiatric } \\
\text { nurse (in 1st year of } \\
\text { a CBT IAOT } \\
\text { training course at } \\
\text { University of } \\
\text { Chiba), translation } \\
\text { of the model }\end{array}$ & $\begin{array}{l}\text { Importance of } \\
\text { understanding } \\
\text { socio-cultural and } \\
\text { historical context } \\
\text { (recent change of } \\
\text { cultural norms led to } \\
\text { patients being } \\
\text { 'caught' between 'old' } \\
\text { and 'new' norms). } \\
\text { Importance of cultural } \\
\text { norms - e.g. Japanese } \\
\text { less likely to express } \\
\text { themselves directly } \\
\text { and employing vague } \\
\text { expressions, also } \\
\text { concealing true } \\
\text { thoughts and feelings. } \\
\text { Behavioural experiments } \\
\text { and opinion surveys } \\
\text { must be constructed } \\
\text { more carefully and in } \\
\text { a culturally sensitive } \\
\text { manner. } \\
\text { Therapist is viewed as } \\
\text { an authority figure. } \\
\text { Careful consideration } \\
\text { for taijin-kyofu-sho }\end{array}$ & $\begin{array}{l}\text { CBT developed in } \\
\text { Western countries } \\
\text { may be effective for } \\
\text { Japanese clients but } \\
\text { caution needs to be } \\
\text { exercised when } \\
\text { designing behavioural } \\
\text { experiments and } \\
\text { adapting CBT for } \\
\text { offensive-subtype } \\
\text { SAD } \\
\text { (taijin-kyofu-sho). } \\
\text { Therapeutic } \\
\text { relationship needs to } \\
\text { be more directive and } \\
\text { formal } \\
\text { (support for Theory } 3 \text { - } \\
\text { although required } \\
\text { modifications seem } \\
\text { to be more } \\
\text { pronounced) }\end{array}$ \\
\hline
\end{tabular}


Table 3. Continued

\begin{tabular}{|c|c|c|c|c|c|}
\hline $\begin{array}{l}\text { Author(s), date } \\
\text { and title }\end{array}$ & $\begin{array}{l}\text { Research } \\
\text { aim }\end{array}$ & $\begin{array}{l}\text { Research } \\
\text { design }\end{array}$ & $\begin{array}{l}\text { Case study } \\
\text { context }\end{array}$ & $\begin{array}{l}\text { Recommendations } \\
\text { for clinicians }\end{array}$ & Findings \\
\hline $\begin{array}{l}\text { Ashworth KJ, } \\
\text { Randall J, } \\
\text { Millen A, } \\
\text { Rosqvist J } \\
\text { (2011). } \\
\text { Culturally } \\
\text { competent } \\
\text { CBT: treating } \\
\text { SAD in a } \\
\text { Korean } \\
\text { immigrant - a } \\
\text { single case } \\
\text { study analysis }\end{array}$ & $\begin{array}{l}\text { To consider } \\
\text { whether CBT } \\
\text { model for } \\
\text { SAD can be } \\
\text { adhered to, } \\
\text { whilst } \\
\text { attending to } \\
\text { pertinent } \\
\text { cultural } \\
\text { factors }\end{array}$ & $\begin{array}{l}\text { Single case } \\
\text { study }\end{array}$ & $\begin{array}{l}\text { USA, Korean } \\
\text { immigrant ( } 21, \\
\text { emigrated to USA at } \\
\text { the age of } 15,6 \\
\text { years prior to } \\
\text { treatment). No } \\
\text { details regarding the } \\
\text { clinician. Treatment } \\
\text { at the university } \\
\text { training clinic. } \\
\text { Language not } \\
\text { considered }\end{array}$ & $\begin{array}{l}\text { Importance of cultural } \\
\text { factors (although these } \\
\text { are not specified). } \\
\text { Importance of cultural } \\
\text { norms (e.g. group } \\
\text { harmony) and values } \\
\text { (value given to } \\
\text { family). } \\
\text { Consideration of } \\
\text { acculturation stage. } \\
\text { Consideration for } \\
\text { taijin-kyofu-sho (need } \\
\text { to consider whether } \\
\text { patient suffers from } \\
\text { SAD or TKS). } \\
\text { Importance of concrete } \\
\text { goals, interventions } \\
\text { focused on solutions. } \\
\text { Importance of } \\
\text { customization of } \\
\text { exposure work }\end{array}$ & $\begin{array}{l}\text { Customization of the } \\
\text { content of the } \\
\text { exposure work is } \\
\text { essential. } \\
\text { Although attention } \\
\text { needs to be paid to } \\
\text { match treatment with } \\
\text { patients' cultural } \\
\text { experiences and } \\
\text { backgrounds, the } \\
\text { treatment protocol } \\
\text { does not need to } \\
\text { deviate from standard } \\
\text { Western CBT } \\
\text { (support for Theory } 3 \text { - } \\
\text { although required } \\
\text { modifications seem } \\
\text { to be less } \\
\text { pronounced and not } \\
\text { clearly detailed) }\end{array}$ \\
\hline
\end{tabular}


Table 3. Continued

\begin{tabular}{|c|c|c|c|c|c|}
\hline $\begin{array}{l}\text { Author(s), date } \\
\text { and title }\end{array}$ & $\begin{array}{l}\text { Research } \\
\text { aim }\end{array}$ & $\begin{array}{l}\text { Research } \\
\text { design }\end{array}$ & $\begin{array}{l}\text { Case study } \\
\text { context }\end{array}$ & $\begin{array}{l}\text { Recommendations } \\
\text { for clinicians }\end{array}$ & Findings \\
\hline $\begin{array}{l}\text { McIndoo CC, } \\
\text { Hopko DR } \\
\text { (2014). } \\
\text { Cognitive- } \\
\text { behavioral } \\
\text { therapy for an } \\
\text { Arab college } \\
\text { student with } \\
\text { social phobia } \\
\text { and } \\
\text { depression }\end{array}$ & $\begin{array}{l}\text { To consider } \\
\text { whether a } \\
\text { manualized CBT } \\
\text { treatment for } \\
\text { SAD (Hope } \\
\text { et al., 2010) } \\
\text { which directly } \\
\text { addresses } \\
\text { cultural issues } \\
\text { and guides } \\
\text { therapists to be } \\
\text { aware of } \\
\text { culturally } \\
\text { specific } \\
\text { interpersonal } \\
\text { behaviours can } \\
\text { be successfully } \\
\text { used with Arab } \\
\text { patients }\end{array}$ & $\begin{array}{l}\text { Single case } \\
\text { study }\end{array}$ & $\begin{array}{l}\text { USA, Arab, 26, male } \\
\text { student (emigrated } \\
\text { to USA with his } \\
\text { family at the age of } \\
\text { 3), treated at a } \\
\text { university } \\
\text { psychological clinic } \\
\text { by a female doctoral } \\
\text { student (ethnicity } \\
\text { not stated). } \\
\text { Language not } \\
\text { considered }\end{array}$ & $\begin{array}{l}\text { Importance of } \\
\text { assessment of cultural } \\
\text { background and its } \\
\text { relation to the } \\
\text { presenting problems. } \\
\text { The need to practice } \\
\text { cultural awareness } \\
\text { (being open, and } \\
\text { frequently discussing } \\
\text { culture). } \\
\text { Attention needs to be } \\
\text { paid to cultural norms } \\
\text { and values (e.g. } a d a b \text { ). } \\
\text { Consideration of } \\
\text { acculturation stage }\end{array}$ & $\begin{array}{l}\text { Manualized CBT } \\
\text { treatment for SAD } \\
\text { (Hope et al., 2010) } \\
\text { can be used when } \\
\text { working with Arab } \\
\text { minority clients, so } \\
\text { long as cultural } \\
\text { awareness is } \\
\text { integrated into the } \\
\text { treatment plan } \\
\text { (support for Theory } 3 \\
\text { with emphasis on } \\
\text { cultural awareness, } \\
\text { rather than specific } \\
\text { modifications) }\end{array}$ \\
\hline
\end{tabular}


Table 3. Continued

\begin{tabular}{|c|c|c|c|c|c|}
\hline $\begin{array}{l}\text { Author(s), date } \\
\text { and title }\end{array}$ & $\begin{array}{l}\text { Research } \\
\text { aim }\end{array}$ & $\begin{array}{l}\text { Research } \\
\text { design }\end{array}$ & $\begin{array}{l}\text { Case study } \\
\text { context }\end{array}$ & $\begin{array}{l}\text { Recommendations } \\
\text { for clinicians }\end{array}$ & Findings \\
\hline $\begin{array}{l}\text { Toyokawa T, } \\
\text { Nedate K } \\
\text { (1996). } \\
\text { Application } \\
\text { of cognitive } \\
\text { behaviour } \\
\text { therapy to } \\
\text { interpersonal } \\
\text { problems: a } \\
\text { case study of } \\
\text { a Japanese } \\
\text { female client }\end{array}$ & $\begin{array}{l}\text { To consider } \\
\text { whether CBT } \\
\text { can be } \\
\text { adapted for } \\
\text { use with } \\
\text { Japanese and } \\
\text { Japanese } \\
\text { American } \\
\text { clients }\end{array}$ & $\begin{array}{l}\text { Single case } \\
\text { study }\end{array}$ & $\begin{array}{l}\text { Japan, Japanese female } \\
\text { client (44) living in } \\
\text { urban area in Japan. } \\
\text { Treated at a private } \\
\text { outpatient mental } \\
\text { health clinic in } \\
\text { Tokyo }\end{array}$ & $\begin{array}{l}\text { Importance of cultural norms } \\
\text { - e.g. norm not to talk } \\
\text { negatively about family } \\
\text { members (CBT focused on } \\
\text { present problems, rather } \\
\text { than past or family). } \\
\text { Importance of understanding } \\
\text { that Asian clients do not } \\
\text { utilize mental health } \\
\text { services until a problem } \\
\text { becomes severe. } \\
\text { Expectations of gains from } \\
\text { early on } \\
\text { Therapist is viewed as an } \\
\text { authority figure/expert. } \\
\text { Therapist more directive. } \\
\text { Culturally taboo topics } \\
\text { (family, sex, familial } \\
\text { shame) not discussed with } \\
\text { strangers - importance of } \\
\text { awareness and not } \\
\text { discussing directly (but } \\
\text { utilizing home works, e.g. } \\
\text { records). } \\
\text { Importance of cultural norms } \\
\text { (e.g. group harmony) }\end{array}$ & $\begin{array}{l}\text { CBT developed in } \\
\text { Western countries } \\
\text { may be effective for } \\
\text { Japanese clients, } \\
\text { keeping in mind } \\
\text { cultural differences in } \\
\text { the client-therapist } \\
\text { relationship, and } \\
\text { norms for the } \\
\text { rationality or } \\
\text { irrationality of beliefs } \\
\text { in a Japanese cultural } \\
\text { context } \\
\text { (support for theory } 3 \text { - } \\
\text { with clear } \\
\text { recommendations for } \\
\text { areas of } \\
\text { modification) }\end{array}$ \\
\hline
\end{tabular}


Table 3. Continued

\begin{tabular}{|c|c|c|c|c|c|}
\hline $\begin{array}{l}\text { Author(s), date } \\
\text { and title }\end{array}$ & $\begin{array}{l}\text { Research } \\
\text { aim }\end{array}$ & $\begin{array}{l}\text { Research } \\
\text { design }\end{array}$ & $\begin{array}{l}\text { Case study } \\
\text { context }\end{array}$ & $\begin{array}{l}\text { Recommendations } \\
\text { for clinicians }\end{array}$ & Findings \\
\hline $\begin{array}{l}\text { *Fink C M, } \\
\text { Turner S M, } \\
\text { Beidel DC } \\
\text { (1996). } \\
\text { Culturally } \\
\text { relevant } \\
\text { factors in the } \\
\text { behavioral } \\
\text { treatment of } \\
\text { social phobia: } \\
\text { a case study }\end{array}$ & $\begin{array}{l}\text { To assess the } \\
\text { impact of } \\
\text { cultural } \\
\text { factors in } \\
\text { behavioural } \\
\text { and cognitive } \\
\text { behavioural } \\
\text { treatments of } \\
\text { social } \\
\text { phobia. }\end{array}$ & $\begin{array}{l}\text { Single case } \\
\text { study }\end{array}$ & $\begin{array}{l}\text { USA, } \\
\text { African-American } \\
\text { female, } 39\end{array}$ & $\begin{array}{l}\text { The importance of } \\
\text { exposure to racially } \\
\text { relevant cues. } \\
\text { Therapists needs to be } \\
\text { alert to the importance } \\
\text { of culturally sensitive } \\
\text { factors in the } \\
\text { acquisition of fear } \\
\text { states and the need to } \\
\text { address these in } \\
\text { therapy }\end{array}$ & $\begin{array}{l}\text { Including cultural } \\
\text { factors in treatment is } \\
\text { effective for the single } \\
\text { case of an } \\
\text { African-American } \\
\text { woman with social } \\
\text { phobia } \\
\text { (support for Theory } 3 \\
\text { with emphasis on } \\
\text { cultural awareness, } \\
\text { rather than specific } \\
\text { modifications) }\end{array}$ \\
\hline
\end{tabular}




\section{Challenges in the delivery of CBT for culturally diverse clients}

The reviewed case studies highlighted certain aspects that may present challenges in the delivery of CBT for culturally diverse clients including: language and level of acculturation (for ethnic minority clients, e.g. Weiss et al., 2011; Ashworth et al., 2011), socio-cultural construction of therapy and therapeutic relationship (e.g. more authoritarian and directive therapist style, the need for a therapy to be more structured, concrete and focused on solutions, McIndoo and Hopke, 2014; Toyokawa and Nedate, 1996; Ashworth et al., 2011; Yoshinaga et al., 2013), potential difficulties in managing expectations, such as, for instance, Japanese clients' wish for quick symptom reduction (Toyokawa and Nedate, 1996) and tackling culturally taboo topics, such as family's past and shame or sex (Toyokawa and Nedate, 1996).

\section{Minor adaptations to improve adherence and engagement with therapy}

The reviewed cases indicate the need to address the potential challenges listed above by introducing modest but culturally important modifications to CBT treatment. The main identified minor adaptations and their potential to improve adherence and engagement with therapy are discussed below.

\section{Language}

Two of the reviewed cases emphasized the role of native languages in therapy (Weiss et al., 2011) and indicated that much more consideration needs to be given to the utilization of native languages in CBT. Clients who do not have English as their first language may find it difficult to access their thoughts or the thoughts can be 'lost in translation', making cognitive work less beneficial. It is important to ask questions around language use in the assessment to gauge the client's proficiency in both languages, to see which language is used for emotional expression and which language is used when thinking. Weiss et al. (2011) advocate the incorporation of native language in CBT, especially in written homework assignments, such as thought records. Yet, asking clients to express themselves in their native languages needs to be introduced carefully, not to give them an impression that a therapist perceives them as unable to speak the language of the dominant culture, as this may perpetuate their fear of social judgement and/or distorted perception of their language proficiency. In the case described by Weiss et al. (2011), a Latino client initially found the suggestion of incorporating Spanish into homework assignments as offensive - suggesting that the therapist thought he was not fluent in English and the treatment progressed in English only until a greater rapport was built. Once the therapist re-introduced the idea of using Spanish, the client reported that he was able to better dispute his automatic thoughts in Spanish and that his thoughts appeared to be more emotionally laden. His subjective units of distress (SUD) ratings appeared to decrease more quickly with the use of a Spanish rational response. For clients whose proficiency in the dominant language (i.e. English) is lower, the use of native language may be even more important as automatic thoughts and core beliefs are said to be experienced in native languages. In the case of a Chinese client (Weiss et al., 2011) completing cognitive restructuring exercises in her primary language led to a much deeper identification and activation of her core beliefs, which then could be challenged more effectively. Weiss et al. (2011) also observed that with clients who are not proficient in the dominant language, 
the therapist may need to slow down the pace of the protocol and it is likely that the treatment will progress more slowly than usual.

\section{Level of acculturation}

The level of post-immigration acculturation may also have a significant impact on the SAD presentation, content of thoughts and internal conflicts, to which therapists need to pay close attention (Ashworth et al., 2011). For instance, some clients in the biculturation phase of acculturation may experience internal conflict or clash of values (home versus host culture values, Ashworth et al., 2011). For other clients some norms of the host culture may be unacceptable, and this can cause significant distress (Weiss et al., 2011). By paying attention to the level of acculturation and potential client's difficulties or internal conflicts, a therapist may be able to bring these issues to the client's awareness and help him or her work through these issues and find solutions.

\section{Socio-cultural construction of therapy and therapeutic relationship}

CBT's conceptualization of the therapeutic relationship centres on collaboration, with the therapist seen as a supporter assisting clients in solving their problems may not be suitable for other contexts (Yoshinaga et al., 2013). In many collectivistic, high-power- distance cultures social relationships are highly hierarchical and social acceptance is derived from higher status, seniority, income or power. Hence the therapist's expertise, status and credentials matter greatly (Toyokawa and Nedate, 1996) and the therapist is viewed as an authority figure and a director - directing clients in the right way, expected to solve patients' problems using therapeutic interventions (Yoshinaga et al., 2013). This has implications for therapy, as clients may be seen as more reliant or dependent on their therapists, remain passive in their treatment, reluctant to express their true thoughts and feelings and act against their own wishes or needs, feeling pressure not to inconvenience, displease or disappoint their therapists (Yoshinaga et al., 2013).

Therefore, therapists need to consider taking on a much more active and directive role (McIndoo and Hopko, 2014) and keep the relationship comparatively vertical rather than horizontal (Toyokawa and Nedate, 1996).

In cases where the therapist is younger or perceived to occupy socially lower position than a client (e.g. a young female therapist treating a male, older client), it may be important to adhere to socially acceptable norms, such as addressing clients formally (not using their first names) and showing respect (e.g. in Latino culture, Weiss et al., 2011).

\section{Structure and content of therapy}

Overall, all case studies reviewed remained faithful to the original CBT structure/protocols, however the order, emphasis and/or style of the delivery was altered, and attention was paid to potential culture-specific content (norms, values, beliefs). Firstly, because of the need to relieve symptoms and increase trust in therapy is particularly pronounced, especially among certain Asian clients (e.g. Japanese), it is advisable to forefront problem solving (Toyokawa and Nedate, 1996) and provide clients with an experience of success/achievement early on. Strong psychoeducation is recommended, and therapists' advice may be presented in a more authoritative style, such as directing clients to engage in challenging tasks (Yoshinaga et al., 2013). Clients coming from collectivistic backgrounds seem to benefit from highly structured 
sessions, concrete goals and interventions strongly focused on solutions in the present moment (McIndoo and Hopko, 2014).

\section{Management of expectations}

The review case studies highlighted the need to understand expectations regarding therapy which stem from cultural constructions of psychological distress and the importance of culturally sensitive response.

Collectivistic principles emphasize a sense of interdependence with significant others and imply that an individual's behaviour is not only a reflection of the self but also the entire family or community. Clients coming from certain collectivistic cultures may show concern over bringing the burden of the stigma and shame on the whole family or community may cause the reluctance to admit to mental health problems (Hsu and Alden, 2008), concealing the fact of seeking or receiving treatment (Ashworth et al., 2011). Hence they may seek treatment only after problems have become quite serious, resulting in significant interference and distress, for which they desire relatively quick symptom reduction (Toyokawa and Nedate, 1996). Therapists may need to keep this factor in mind and consider how to carefully manage their clients' expectations.

\section{Culturally taboo topics}

It is important to be mindful of taboo topics and culturally restrictive norms (Ashworth et al., 2011; Weiss et al., 2011) and avoid exploration of negative aspects of clients' childhood, family issues, family members and past history that may reflect badly on the family (Toyokawa and Nedate, 1996, Ashworth et al., 2011).

In such cases perhaps therapists should not entertain engaging significant others in therapy and should not dwell on the family's past. Instead the focus should be more on the 'here' and 'now' and conversations regarding significant others have to be conducted carefully. Selfdisclosure needs to be elicited sensitively - it may be more appropriate to restrict disclosure to indirect (written, outside the therapy room) forms (Toyokawa and Nedate, 1996).

Furthermore, therapists need to be mindful of the content they wish to elicit, work with or emphasize. For instance, leading the client towards a more assertive and independent attitude may not work for Japanese clients because this may conflict with the value of group harmony, which then, in turn, may have negative social consequences for them (Toyokawa and Nedate, 1996).

When constructing behavioural experiments, therapists need to consider cultural restrictions, such as the issue of concealment of true feelings or the fact that it is more acceptable to speak to same-sex individuals in Arab culture. Hence behavioural experiments may need to be restricted to same-sex interactions (McIndoo and Hopko, 2014), or replaced with opinion surveys - to elicit more objective responses from multiple respondents (Toyokawa and Nedate, 1996).

In cases where racial or cultural biases need to be challenged, it may be important to construct exposure to address this. For instance, in the case of an African American woman who felt excluded by her White peers and whose fear of social interactions was more intense when racial encounters involved White males, inter-racial encounters were included in in vivo exposures (Fink et al., 1996). Understanding cultural values and beliefs can facilitate therapy 
process. For instance, for Latino clients understanding the role of family may provide insights into their core beliefs and fears (e.g. fear of being alone, Weiss et al., 2011).

\section{Discussion}

This literature review aimed to consider whether any culturally specific modifications are required when applying CBT to culturally diverse SAD sufferers and, if yes, whether the introduction of such modifications increases the treatment compliance and its outcomes and in what way.

All reviewed case studies indicated that CBT can be applied to culturally diverse SAD sufferers without major modifications to the treatment. This therefore gives support to Theory 3: 'modest' cultural modifications may be beneficial (Chapman et al., 2013; Weiss et al., 2011), identified as one of the main three competing theories at the stage of progressive focusing in the literature review (see 'Realist review methodology - stages of the literature search strategy' section).

Although the focus of the reviewed literature was on CBT for SAD, the claims made in the reviewed case studies appear to relate more generally to CBT, rather than CBT for social anxiety within this client group. This may be surprising given the focus of the case studies. Yet, it is congruent with the finding that CBT can be applied to culturally diverse SAD sufferers without major modifications to the treatment. It seems that it is not the content of the model and treatment that requires modification, but the onus is on the cultural awareness and sensitivity of the therapists and his/her ability to employ minor modifications that can improve the treatment.

The available literature points to the agreement that the lack of consideration of cultural norms and values and socio-cultural contexts may impede access to and engagement with therapy (Chueng, 2012; Shedhadeh et al., 2016; Van Loon et al., 2013). Some minority groups have experienced significant oppression/prejudice and may have concerns trusting healthcare professionals (Weiss et al., 2011; Fink et al., 1996) and they are less likely to receive potentially adequate care (Weisberg et al., 2014). For instance, Chinese clients tend to under-utilize mainstream health services (Hsu and Alden, 2008; Hsu et al., 2012), not because they experience less or less serious mental health problems but because they tend to seek treatment only after problems have become quite serious, resulting in significant interference and distress, for which they desire relatively quick symptom reduction (Toyokawa and Nedate, 1996; Weiss et al., 2011). Much lower prevalence rates of SAD among Asians (Ashworth et al., 2011; Hofmann et al., 2010) may potentially stem from cultural construction of psychological distress as a lack of willpower and self-control and something unacceptable (Toyokawa and Nedate, 1996). Many collectivistic cultures employ strict rules of socially acceptable behaviour, hence social evaluation is highly salient and any small deviation from socio-cultural norms may have significant negative repercussions (e.g. rapid and permanent social outcast, McIndoo and Hopko, 2014). Among cultures that impose rigid and disciplined moral codes and rituals (Iancu et al., 2011; Greenberg et al., 2004) the likelihood of responding to social situations with extreme fear and anxiety is heightened (McIndoo and Hopko, 2014). Collectivistic principles emphasize a sense of interdependence with significant others and imply that an individual's behaviour is not only a reflection of the self but also the entire family or community. The concern over bringing the burden of the stigma and shame on the whole family or community may cause the reluctance to admit to mental health problems 
(Hsu and Alden, 2008), concealing the fact of seeking or receiving treatment, reluctance to involve or discuss it with significant others and the reluctance to discuss any family issues or past history that may reflect badly on the family (Ashworth et al., 2011).

Therapists need to be mindful of various cultural constructions of mental health illness, potential severity of symptoms, barriers to accessing therapy and taboo topics. Therapists should also be mindful of the tendency of certain Asian clients (e.g. Japanese) to express themselves less directly, employing vague expressions and concealing true thoughts and feelings (Yoshinaga et al., 2013). The impact of this goes far beyond initial distrust and reservations around therapy. For instance, behavioural experiments may be less successful if a client believes that the absence of the feared response (e.g. criticism or disgust) is down to the other person being able to conceal their true feelings (Yoshinaga et al., 2013). Due to the importance of social consciousness/awareness of hurting other people's feelings (Schreier et al., 2010) and the need to protect group harmony (Hofmann et al., 2010), Asian clients may tend to agree with the therapist's statements even if they disagree, ask fewer questions and interact less with their therapists, which may impede therapy (Iwamasa et al., 2006). Overall, the case studies reviewed emphasize that it is paramount that therapists continually monitor their clients' understanding of session material, assessment instruments and their feelings towards the process and therapeutic interaction (Weiss et al., 2011).

Cultural/ethnic matching of therapists to clients is reported as one strategy that can enhance cultural appropriateness of therapy (Carter et al., 2012). However, most of the reviewed case studies did not employ this strategy. Instead, the emphasis was placed on the importance of awareness of cultural norms, values and socio-cultural context and remaining alert to potential cultural factors in assessment and therapy.

Moreover, it is important to consider culturally sensitive factors in the acquisition of fear states (Fink et al., 1996) and culturally specific expression of SAD, such as the concept of TKS or aymat zibur ('fear of the community') among ultra-orthodox Jews (Hofmann et al., 2010). Understanding specific socio-cultural changes, such as change of norms over generations and conflict that these may evoke in clients can also be an important factor (Yoshinaga et al., 2013) and hence it would be advisable to acquire culture-specific knowledge - both through broader research and directly from clients, when treating clients of a particular cultural background.

\section{Summary and concluding discussion}

Summary - evidence for minor modifications of SAD treatment for culturally diverse populations

This literature review focused on seven case studies of cultural adaptations of CBT treatment for culturally diverse SAD sufferers, presented within six journal articles. The treatment outcomes were generally promising in all cases, reporting significant decrease of SAD symptoms, maintained over time and the success of therapy was often attributed to the culturally specific modifications introduced. However, there was little discussion or consideration given to other, non-culture-related, factors that could potentially contribute to the success of therapy and this will require further investigation. Moreover, many aspects discussed in the case studies and reported in the Results section within this review seem to be more generic to CBT, rather than specific to CBT for anxiety. This, as suggested above, 
can be explained by the findings indicating that only minor modifications are required, and the adjustments suggested by the authors of the cases did not require modification to the SAD model and treatment.

In particular, therapists practised cultural awareness and remained open to discussing culture and were attentive to cultural norms, values and beliefs and socio-cultural contexts as well as culture-specific expressions of SAD and the level of acculturation. They modified elements of CBT treatment for SAD and adjusted their therapeutic style to match clients' cultural expectations. In some cases, they successfully utilized native languages of the clients.

\section{Limitations and future directions for research}

The case studies reported were written by clinicians from the perspective of practice, utilized various models and protocols and reported patients' improvements on a variety of measures. This made cross-case study comparisons difficult. None of them included patients' direct observations of their experiences of CBT. As indicated, this area is largely underresearched with conflicting evidence presented in quantitative studies, ranging from the need for systematic, cultural adaptations of therapy to no need for any cultural modifications and virtually no qualitative studies conducted, apart from single case studies. There was also little thought given to any other, non-culture-related factors that could have increased the treatment compliance and its outcomes. Larger scale observational or quantitative studies could explore this further.

The next step in qualitative investigation of this area should involve exploration of the views of culturally diverse clients and their therapists and utilize one battery of measurements across all cases. Treatments should be centred on the same model and/or protocol across studies to enable some comparisons. Finally, all the cases came from the USA or Japan and there is a need for further evidence coming from other countries. The searches could also be conducted in languages other than English and this could potentially widen the evidence base. However, this was not possible due to financial and time constraints within this review. It would also be interesting to investigate whether cultural modifications to CBT treatment are required for SAD sufferers from non-collectivistic cultures.

\section{Conclusion}

This article aimed to familiarize the readers with the overview of literature on cultural aspects of social anxiety and enable them to consider whether cultural adaptations to the treatment protocol of SAD are necessary (and if so, to what extent). The author invites practitioners to reflect on their own practice and potential cultural modifications they have already introduced or may consider introducing in their own clinical work with culturally diverse socially anxious clients. The article points to the fact that further research (going beyond the case study approach) is necessary.

In conclusion, the discussed cases indicate that CBT can be an acceptable and effective treatment for culturally diverse SAD sufferers with 'modest' modifications, without major diversions from the original CBT models and protocols, and that applying them increases the treatment compliance and its outcomes. However, these findings must be treated with caution and more methodologically rigorous research (both qualitative and quantitative) is needed to more fully understand what works, for whom and in what circumstances. 


\section{Main points}

(1) This article explored and reviewed the literature on cultural aspects of social anxiety in order to determine whether cultural adaptations to the treatment protocol of SAD are necessary (and if so, to what extent).

(2) The available evidence indicates that CBT can be an acceptable and effective treatment for culturally diverse SAD sufferers with 'modest' modifications, without major diversions from the original CBT models and protocols, and that applying them increases the treatment compliance and its outcomes.

(3) The available evidence is scant and comes mainly from case studies. More methodologically rigorous research (both qualitative and quantitative) is needed to more fully understand what works, for whom and in what circumstances

\section{Ethical statement}

The author has abided by the Ethical Principles of Psychologists and Code of Conduct, as set by the APA (2017). No ethical approval was required as the article is a review of the literature and already published case studies were used to collate the data.

\section{Conflict of interest}

Dr Maja Jankowska has no conflict of interest with respect to this publication.

\section{Financial support}

This research received no specific grant from any funding agency, commercial or not-for-profit sectors.

\section{Recommended follow-up reading}

For general discussion on psychological treatment of ethnic minority clients:

Zane N, Bernal G and Leong FTL (eds) (2016). Evidence-Based Psychological Practice With Ethnic Minorities: Culturally Informed Research and Clinical Strategies. American Psychological Association: Washington DC.

For discussion on cultural aspects of social anxiety:

Hofmann SG, Asnaani A and Hinton DE (2010). Cultural aspects in social anxiety and social anxiety disorder. Depression and Anxiety, 27, 1117-1127. doi: 10.1002/da.20759

\section{References}

Acaturk C, Cuijpers P, van Straten A and de Graaf R (2009). Psychological treatment of social anxiety disorder: a meta-analysis. Psychological Medicine, 39, 241-245.

Ashworth KJ, Randall J, Millen A and Rosqvist J (2011). Culturally competent CBT: treating SAD in a Korean immigrant - a single case analysis. Clinical Case Studies, 10, 449-465. doi: $10.1177 / 1534650111435163$ 
American Psychological Association (1990). Guidelines for providers of psychological services to ethnic, linguistic, and culturally diverse populations. Available at: http://www.apa.org/pi/oema/ resources/policy/provider-guidelines.aspx (accessed 12 December 2016).

American Psychiatric Association (2013). Diagnostic and Statistical Manual of Mental Disorders: DSM-5. Washington, DC: American Psychiatric Association.

Bernal G and Scharrón-del-Río MR (2001). Are empirically supported treatments valid for ethnic minorities? Toward an alternative approach for treatment research. Cultural Diversity and Ethnic Minority Psychology, 7, 328-342.

Carter MM, Mitchell FE and Sbrocco T (2012). Treating ethnic minority adults with anxiety disorders: current status and future recommendations. Journal of Anxiety Disorders, 26, 488-501. doi: 10.1016/j.janxdis.2012.02.002

Castro FG, Barrera M Jr and Holleran Steiker LK (2010). Issues and challenges in the design of culturally adapted evidence-based interventions. Annual Review of Clinical Psychology, 6, 213-239.

Chapman LK, DeLapp RCT and Williams M (2013). Cognitive-behavioural treatment of social anxiety among ethnic minority patients. Part 2: Bridging the gap in treatment. Directions in Psychiatry, 33, 163-176.

Chawdhary N, Jotheeswaran AT, Nadkarni A, Hollon SD, King M, Jordans MJD, Rahman A, Verdeli H, Araya R and Patel V (2014). The methods and outcomes of cultural adaptations of psychological treatments of depressive disorders: a systematic review. Psychological Medicine, 44, 1131-1146. doi: 10.1017/S0033291713001785

Chen J, Nakano Y, Ietzugu T, Ogawa S, Funayama T, Watanabe N et al. (2007). Group cognitive behavior therapy for Japanese patients with social anxiety disorder: preliminary outcomes and their predictors. BMC Psychiatry, 7. doi: 10.1186/1471-244X-7-69

Chueng FM (2012). Maintaining culture in psychology. America Psychologist, 76, 721-730.

Council of National Psychological Associations for the Advancement of Ethnic Minority Issues (2003). Psychological treatment of ethnic minority populations. Washington, DC: Association of Black Psychologists. Available at: https://www.apa.org/pi/oema/resources/ brochures/treatment-minority.pdf (accessed 12 December 2016).

Fink CM, Turner SM and Beidel DC (1996). Culturally relevant factors in the behavioral treatment of social phobia: a case study. Journal of Anxiety Disorders, 10, 201-209. doi: 10.1016/0887-6185(96)00005-9

Flick U (1995) An Introduction to Qualitative Research. Thousand Oaks, CA: Sage.

Greenberg D, Stravynski A and Bilu Y (2004). Social phobia in ultra-orthodox Jewish males: culturebound syndrome or virtue? Mental Health, Religion and Culture, 7, 289-305.

Iwamasa GY (2003). Recommendations for the treatment of Asian American/Pacific Islander populations. In Psychological Treatment of Ethnic Minority Populations (pp. 8-12). Washington, DC: Association of Black Psychologists.

Iwamasa GY, Hsia C and Hinton D (2006). Cognitive-behavioral therapy with Asian Americans. In PA Hays and GY Iwamasa (eds), Culturally Responsive Cognitive-Behavioral Therapy: Assessment, Practice and Supervision (pp. 117-140). Washington, DC: American Psychological Association.

Husain N, Afsar S, Ara J, Fayyaz H, ur Rahman R, Tomenson B et al. (2014). Brief psychological intervention after self-harm: randomised controlled trial from Pakistan. British Journal of Psychiatry, 204, 462-70.

Husain MO, Chaudhry IB, Mehmood N, Rehman R ur, Kazmi A, Hamirani M et al. (2017). Pilot randomised controlled trial of culturally adapted cognitive behavior therapy for psychosis (CaCBTp) in Pakistan. BMC Health Services Research, 17, 808. http://doi.org/10.1186/s12913-017-2740-z 
Hsu L and Alden LE (2008). Cultural influences on willingness to seek treatment for social anxiety in Chinese- and European-heritage students. Cultural Diversity and Ethnic Minority Psychology, 14, 215-223. doi: 10.1037/1099-9809.14.3.215

Hsu L, Woody SR, Lee H, Peng Y, Zhou X and Ryder AG (2012). Social anxiety among East Asians in North America: East Asian socialization or the challenge of acculturation? Cultural Diversity and Ethnic Minority Psychology, 18, 181-191. doi: 10.1037/a0027690

Hofmann SG, Asnaani A and Hinton DE (2010). Cultural aspects in social anxiety and social anxiety disorder. Depression and Anxiety, 27, 1117-1127. doi: 10.1002/da.20759

Hunsley J, Elliott K and Therrien Z (2014). The efficacy and effectiveness of psychological treatments for mood, anxiety, and related disorders. Canadian Psychology/Psychologie Canadienne, 55, $161-176$.

Hofmann SG and Smits JA (2008). Cognitive-behavioral therapy for adult anxiety disorders: a metaanalysis of randomized placebo-controlled trials. Journal of Clinical Psychiatry, 69, 621-632.

Hope DA, Heimberg RG and Turk CL (2010). Managing Social anxiety. A Cognitive-Behavioral Therapy Approach (2nd edn). New York, NY: Oxford University Press.

Iancu I, Sarel A, Avital A, Abdo B, Joubran S and Ram E (2011). Shyness and social phobia in Israeli Jewish vs Arab students. Comprehensive Psychiatry, 52, 708-714.

Iwamasa GY (2003). Recommendations for the treatment of Asian American/ Pacific Islander populations. In Psychological treatment of Ethnic Minority Populations (pp. 8-12). Washington, DC: Association of Black Psychologists.

Kleinknecht RA, Dinnel DL, Kleinknecht EE, Hiruma N and Harada N (1997). Cultural factors in social anxiety: a comparison of social phobia symptoms and Taijin kyofusho. Journal of Anxiety Disorders, 11, 157-177.

Leslie L (2013). Taijin-Kyofu-Sho: a subtype of social anxiety. Open Journal of Psychiatry, 3, 393-398.

Lincoln YS and Guba EG (1985) Naturalistic Enquiry. Beverley Hills, CA: Sage.

McIndoo C and Hopko D (2014). Cognitive-behavioral therapy for an Arab college student with social phobia and depression. Clinical Case Studies, 13, 128-145.

McLeod J (2001). Qualitative Research in Counselling and Psychotherapy. London: Sage.

McLeod J and Elliott R (2011). Systematic case study research: a practice-oriented introduction to building an evidence base for counselling and psychotherapy. Counselling and Psychotherapy Research, 11, 1-10. doi: 10.1080/14733145.2011.548954

Naeem F, Saeed S, Irfan M, Kiran T, Mehmood N, Gul M et al. (2015). Brief culturally adapted CBT for psychosis (CaCBTp): a randomized controlled trial from a low income country. Schizophrenia Research, 164, 143-148.

Pawson R, Greenhalgh T, Harvey G and Walshe K (2005). Realist review - a new method of systematic review designed for complex policy interventions. Journal of Health Services Research and Policy, 10, 21-34. doi: 10.1258/1355819054308530

Schreier S, Heinrichs N, Alden L, Rapee RM, Hofmann SG, Chen J et al. (2010). Social anxiety and social norms in individualistic and collectivistic countries. Depression and Anxiety, 27, 1128-1134.

Shedhadeh MH, Heim E, Chowdhary N, Maercker A and Albanese E (2016). Cultural adaptation of minimally guided interventions for common mental disorders: a systematic review and meta-analysis. JMIR Mental Health, 3, e44.

Shirotsuki K, Kodama Y and Nomura S (2014). The preliminary study of individual cognitive behavior therapy for Japanese patients with social anxiety disorder. Psychological Services, 11, 162170. doi: $10.1037 / \mathrm{a} 0034781$

Stein DJ (2009). Social anxiety disorder in the West and in the East. Annals of Clinical Psychiatry, 21, $109-117$.

Stewart RE and Chambless DL (2009). Cognitive-behavioral therapy for adult disorders in clinical practice: a meta-analysis of effectiveness studies. Journal of Consultng and Clinical Psychology, 77, 595-606. 
Sue S (2003). In defense of cultural competency in psychotherapy and treatment. American Psychologist, 58, 964-970.

Sue DW and Sue D (2008). Counselling the Culturally Diverse: Theory and Practice. New Jersey, NJ: Wiley and Sons.

Tellis W (1997). Introduction to Case Study. The Qualitative Report, 3(2). Available at: http://www.nova.edu/ssss/QR/QR3-2/tellis1.html (accessed 10 December 2016).

Toyokawa T and Nedate K (1996). Application of cognitive behaviour therapy to interpersonal problems: a case study of a Japanese female client. Cognitive and Behavioural Practice, 3, 289-302.

Weiss BJ, Singh JS and Hope DA (2011). Cognitive-behavioural therapy for immigrants presenting with social anxiety disorder: two case studies. Clinical Case Studies, 10, 324-342. doi: 10.1177/1534650111420706

Van Loon A, van Schaik A, Dekker J and Beekman A (2013). Bridging the gap for ethnic minority adult outpatients with depression and anxiety disorders by culturally adapted treatments. Journal of Affective Disorders, 147, 9-16.

Weisberg RB, Beard C, Moitra E, Dyck I and Keller MB (2014). Adequacy of treatment received by primary care patients with anxiety disorders. Depression and Anxiety, 31, 443-450.

Voss Horrell SC (2008). Effectiveness of cognitive-behavioral therapy with adult ethnic minority clients: a review. Professional Psychology: Research and Practice, 39, 160-168. doi: 10.1037/0735-7028.39.2.160

Yin RK (2009). Case Study Research: Design and Methods (4th edn). Thousand Oaks, CA: Sage.

Yoshinaga N, Kobori O, Iyo M and Shimizu E (2013). Cognitive behaviour therapy using the Clark and Wells model: a case study of a Japanese social anxiety disorder patient. the Cognitive Behaviour Therapist, 6, e.3. doi: https://doi.org/10.1017/S1754470X13000081

\section{Learning objectives}

(1) To familiarize readers with the review of the literature on cultural aspects of social anxiety disorder.

(2) To enable readers to consider whether cultural adaptations to the treatment protocol of SAD are necessary, and if so, to what extent.

(3) To encourage practitioners to reflect on their own practice and potential cultural modification they may consider when treating diverse SAD sufferers.

(4) To encourage researchers to conduct further research, taking the research beyond the case studies' approach. 